\title{
ALLEVIATION OF FLUORIDE INDUCED ALTERATIONS IN ANTIOXIDANT STATUS AND FECUNDITY OF SPERMATOZOA OF RATS BY BOERHAAVIA DIFFUSA L.
}

\author{
SHASHI A. , IMTIAZA KHAN \\ Department of Zoology and Environmental Sciences, Punjabi University Patiala 147002, Punjab, India \\ Email: Shashiuniindia@yahoo.co.in
}

Received: 14 Jun 2017 Revised and Accepted: 31 Aug 2017

\section{ABSTRACT}

Objective: The present study focused on the effect of oral administration of sodium fluoride on antioxidant status and fecundity of spermatozoa of rats and also to evaluate the ameliorative effect of Boerhaavia diffusa L.

Methods: Wistar male rats (weighing 100-150g) were administered sodium fluoride (at three different doses 100, $200 \mathrm{and} 300 \mathrm{ppm} / \mathrm{kg}$ BW) daily for 20 and $40 \mathrm{~d}$. At the end of the experimental period, half of the animals were sacrificed and their epididymis was removed. Remaining half rats were administered B. diffusa (250 and $500 \mathrm{mg} / \mathrm{kg} \mathrm{BW}$ ) for $20 \mathrm{~d}$. Level of malondialdehyde (MDA), the activity of superoxide dismutase (SOD) and catalase (CAT) was estimated. Sperm morphology, count, motility and viability were also determined.

Results: There was a dose-dependent significant decrease in activity of SOD $(p<0.01)$ and CAT $(p<0.05)$, and increase ( $<<0.01)$ in the level of MDA in experimental rats as compared to the control group. Sperm count, motility and viability were also decreased significantly ( $p<0.0001)$ in rats treated with fluoride. The fluorotic rats exhibited morphological abnormalities in the head (amorphous, hookless, double headed and bent), tail (coiled, hairpin looped, double-tailed) and body (short, large and presence of protoplasmic process) of spermatozoa as compared to control group. These toxic effects were reversed by the administration of leaf extract of Boerhaavia diffusa $\mathrm{L}$.

Conclusion: The results suggest that Boerhaavia diffusa L. extract attenuates fluoride exerted disruptions to spermatozoa.

Keywords: Boerhaavia diffusa L., Catalase, Malondialdehyde, Sodium fluoride, superoxide dismutase, Sperm quality

(C) 2017 The Authors. Published by Innovare Academic Sciences Pvt Ltd. This is an open-access article under the CC BY license (http://creativecommons.org/licenses/by/4.0/) DOI: http://dx.doi.org/10.22159/ijpps.2017v9i10.20695

\section{INTRODUCTION}

Exposure to environmental pollutants has increased and contributed to several reproductive health problems in both humans and animals [1-2]. Various researchers have been conducted to explore the relationship between fluoride ingestion and reproductive structure in animal models [3].

Sperm generated in the process of spermatogenesis are highly specialized and condensed cells, which functions in transporting and delivering the male genetic information to the descendant during the fertilization of the oocyte. Sperm quality is one of the important indices of male reproductive function. A literature survey has revealed that fluoride inhibits sperm function, morphology, motility, induce sperm apoptosis and interrupt the sperm function, including capacitation, hyper activation and the acrosome reaction [4-5] all of which are the key process in fertilization, both in vivo and in vitro. Additionally, according to National Research Council annual report [6], fluoride is an endocrine disruptor altering normal endocrine functions thus might affect sperm function by binding to its receptors on spermatozoa.

Boerhaavia diffusa L. (Nyctaginacea) is an important medicinal plant much used in Ayurveda and Unani medicines and other traditional medicines in many parts of the world. It was used to treat seminal weakness and blood pressure [7]. This plant rejuvenates liver, male reproductive system and another organ system; increases libido and quality and quantity of semen [8]. Ethanolic plant extract possess significant levels of enzymatic and non-enzymatic antioxidants and have effective and therapeutic antioxidant potential against various inflammatory diseases [9].

The present study was designed to investigate the effect of fluoride on the antioxidant status and sperm quality parameters and to evaluate the ameliorative effect of $B$. diffusa leaf extract.

\section{MATERIALS AND METHODS}

\section{Materials}

Animals

Wistar male rats weighing between 100-150 g were maintained at a standard temperature $\left(22-25^{\circ} \mathrm{C}\right), 12 / 12$-h light/dark cycle and were given standard rat pellet diet obtained from Hindustan lever Ltd., Mumbai and water were supplied ad libitum. The experiments were performed under the approval of Institutional animal ethics committee, Punjabi University Patiala (Approval number 107/99/CPCSEA-2012-11).

\section{Chemicals and reagents}

Sodium fluoride (Guaranteed Reagent) was purchased from Merck Specialties Pvt. Ltd., India. Sodium fluoride was dissolved in water and administered to animals through oral gavage. All others chemicals, solvents and reagents used in the study were of analytical grade commercially available.

\section{Preparation of plant extract}

The leaf extract of $B$. diffusa was prepared by the method of Narendhirakannan, et al. [10].

\section{Experimental design}

After acclimatization to the environment for one week, the animals were randomly divided into six groups with twelve animals in each group. The first group served as normal control (C1) administered with $1 \mathrm{ppm}$ deionized water)/kg BW/day. The remaining three experimental groups received 100, 200 and 300 $\mathrm{ppm}$ sodium fluoride $(\mathrm{NaF}) / \mathrm{kg} \mathrm{BW} /$ day. All the treatments were given daily by oral gavage for 20 and $40 \mathrm{~d}$. At the end of the experimental period, half of the animals were sacrificed and their epididymis was removed. Remaining half rats were posttreated with B. diffusa (250 and $500 \mathrm{mg} / \mathrm{kg} \mathrm{BW}$ ) for next $20 \mathrm{~d}$. 
Last two groups were kept as a positive control I (C2) and positive control II (C3) administered with 250 and $500 \mathrm{mg} / \mathrm{kg}$ $\mathrm{BW} /$ day $B$. diffusa leaf extract, respectively. At the end of the experimental period, rats were fasted overnight and sacrificed under ether anesthesia.

\section{Methods}

\section{Sample preparation}

Epididymis was minced in $1 \mathrm{ml}$ phosphate buffer Saline (pH 7.4) and centrifuged at $3000 \mathrm{rpm}$ for $10 \mathrm{~min}$ and collected the seminal plasma and the spermatozoa.

\section{Malondialdehyde (MDA)}

MDA level in the spermatozoa of control, fluoride and plant extract treated rats was determined by the method of Ohkawa, et al. [11].

\section{Superoxide dismutase (SOD) and catalase (CAT) activity}

The activity of SOD was determined by the method of Das, et al. [12]. The activity of CAT was determined by the method of Aebi [13].

\section{Sperm morphology assay}

A fine epididymal sperm suspension was made and stained with 0.2 $\mathrm{ml}$ of $1 \%$ aqueous eosin. About 1 drop of stained suspension was placed on the clean slide. It was dried and mounted in DPX. Slides were examined for sperm shape abnormalities [14].

\section{Scanning electron microscopy}

Epididymis was dissected out and washed briefly in normal saline solution. It was cut into pieces washed in $0.1 \mathrm{M}$ phosphate buffer, were fixed in karnovsky's fluid for overnight for SEM study. After fixation in karnovsky's fixative, the specimens were washed in $0.1 \mathrm{M}$ phosphate buffer and then fixed for 1 hour in $0.5 \%$ osmium tetraoxide in the same buffer. After a few washes in $0.1 \mathrm{M}$ phosphate buffer, the specimens were dehydrated through ascending grades of acetone. After critical point drying followed by coating with platinum, the tissue was examined under a scanning electron microscope [15].

\section{Sperm count, motility and viability}

The number of spermatozoa and their motility was calculated according to WHO guidelines. Sperm viability was estimated by assessing the membrane integrity of the cells by dye exclusion method of Eliasson [16].

\section{Statistical analysis}

Results were expressed as mean \pm SD. All analyses were performed using SPSS 17.0 statistical software (IBM). Statistical significance of the difference between the experimental groups was evaluated by one-way ANOVA followed by Bonferroni and Dunnetts $t$ ( 2 sided) multiple comparison tests. The correlation between two variables was analyzed by STATISTICA 7 software. $\mathrm{p}<0.05$ was considered statistically significant.

\section{RESULTS}

\section{Malondialdehyde (MDA) levels}

It was observed that the level of MDA in spermatozoa of test rat increased significantly $(\mathrm{p}<0.0001)$ after $20(\mathrm{~F}=67.041)$ and $40 \mathrm{~d}$ $(\mathrm{F}=445.857)$ of fluoride treatment.

Bonferroni multiple comparison tests after ANOVA displayed a significant increase in the MDA level in spermatozoa between and within all groups after $20(95 \% \mathrm{CI}=-0.0245$ to- $0.0071, \mathrm{p}<0.01)$ and $40 \mathrm{~d}(95 \% \mathrm{Cl}=-0.0557$ to- $0.0663, \mathrm{p}<0.0001)$ of fluoride intoxication (fig. 1).

Dunnetts t ( 2 sided) multiple comparison test revealed that MDA level in spermatozoa was significantly $(\mathrm{p}<0.0001)$ decreased in all groups post treated with $250(95 \% \mathrm{Cl}=-0.0299$ to- 0.0722$)$ and 500 $\mathrm{mg} / \mathrm{kg}$ bw/day $(95 \% \mathrm{Cl}=-0.0396$ to-0.0861) of plant leaf extract (fig. 2).

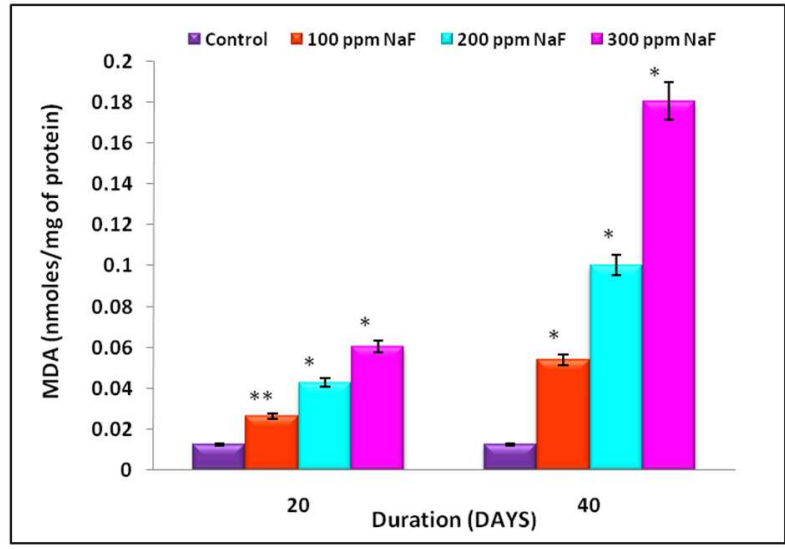

Fig. 1: Level of malondialdehyde (MDA) in spermatozoa of control and NaF treated rats, values are expressed as mean \pm SD. * $p<0.0001$ and $^{* *} \mathbf{p}<0.01 \mathrm{NaF}$ treated groups compared with control

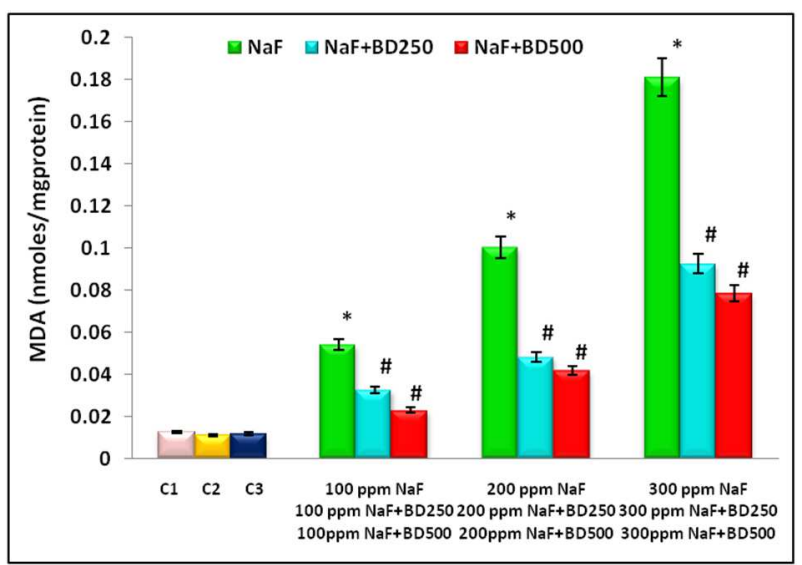

Fig. 2: Level of malondialdehyde (MDA) in spermatozoa of control (C1), positive controls (C2 and C3), NaF treated and combination of $\mathrm{NaF}$ and leaf extract treated group, values are represented as mean $\pm S D$. ${ }^{*} p<0.0001$ compared with control (C1). ${ }^{\#} \mathbf{p}<\mathbf{0 . 0 0 0 1}$ compared to respective NaF treated group

Pearson's bivariate correlation analysis showed significant, $(p<0.0001)$ positive relationship between concentration of fluoride and level of MDA in spermatozoa of test rats after $20(r=0.896$, fig. $3 \mathrm{~A})$ and $40 \mathrm{~d}(\mathrm{r}=0.918$, fig. 3B) of fluoride treatment.

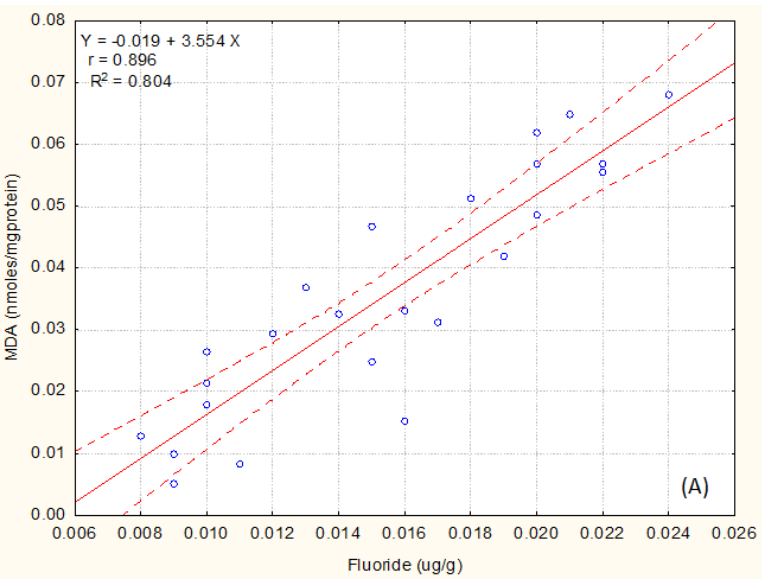




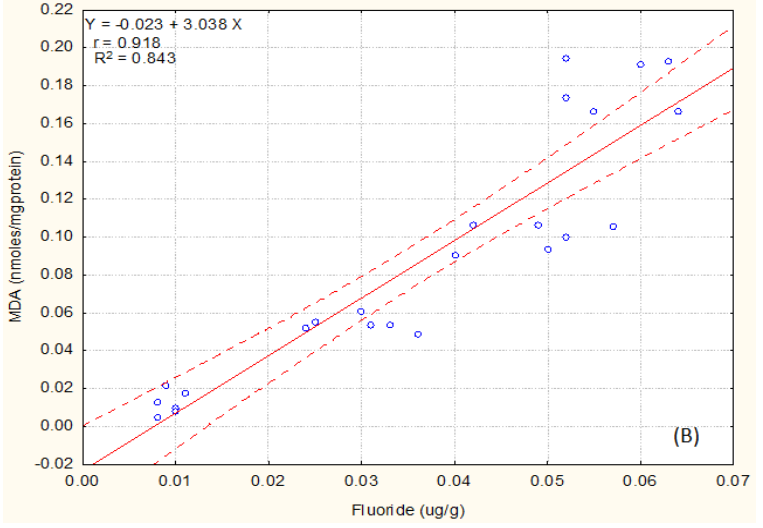

Fig. 3: Correlation and linear regression between level of fluoride and MDA in spermatozoa after (A) 20 and (B) $40 \mathrm{~d}$ of fluoride intoxication

\section{Superoxide dismutase (SOD) activity}

The activity of SOD in spermatozoa of test rat exhibited a significant decrease after $20(\mathrm{~F}=7.079, \mathrm{p}<0.01)$ and $40 \mathrm{~d}(\mathrm{~F}=36.600, \mathrm{p}<0.0001)$ of fluoride treatment.

Bonferroni multiple comparison test after ANOVA displayed a significant decrease $(\mathrm{p}<0.0001)$ in the activity of SOD between and within groups after $40 \mathrm{~d}(95 \% \mathrm{Cl}=0.3329$ to 1.1151$)$ of fluoride exposure (fig. 4).

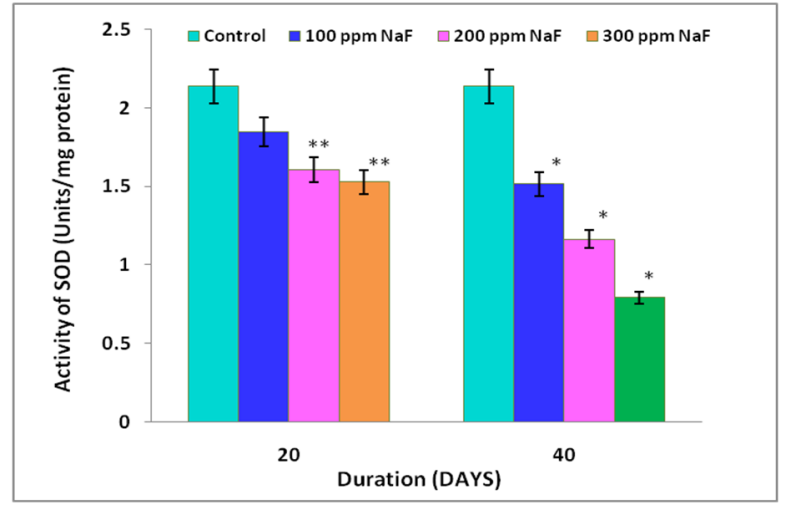

Fig. 4: Activity of SOD in spermatozoa in control and NaF treated rats. Values are expressed as mean $\pm S D$. ${ }^{*} p<0.0001$ and ${ }^{* *} \mathrm{p}<0.01 \mathrm{NaF}$ treated groups compared with control

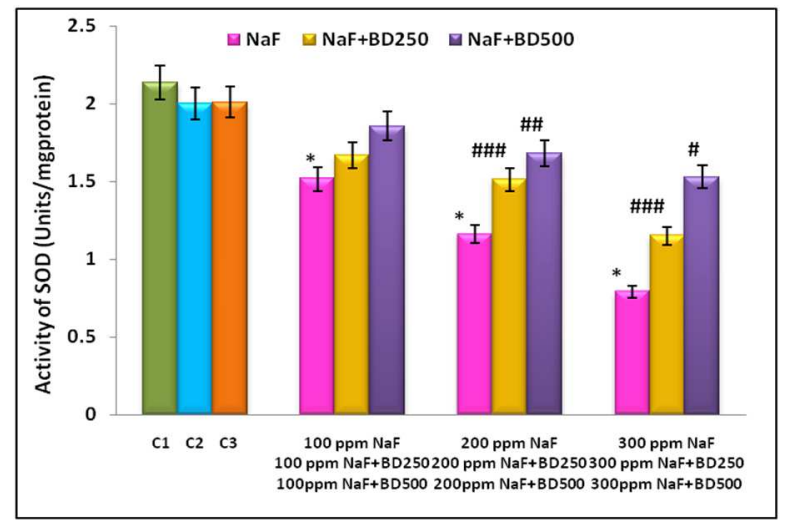

Fig. 5: Activity of SOD in spermatozoa of control (C1), positive control (C2 and C3), NaF treated and combination of NaF and leaf extract treated group, values are represented as mean $\pm \mathrm{SD}$. ${ }^{*} \mathbf{p}<0.0001$ compared with control (C1). ${ }^{\#} \mathbf{p}<0.001,{ }^{\# \#} \mathbf{p}<0.01$ and $\# \#$ \# $<0.05$ compared to respective NaF treated group
Dunnetts $t$ ( 2 sided) multiple comparison test explained that activity of SOD was increased significantly in rats ameliorated with 250 $(95 \% \mathrm{CI}=0.0102$ to $0.6472, \mathrm{p}<0.05)$ and $500 \mathrm{mg} / \mathrm{kg}$ bw/day $(95 \%$ $\mathrm{CI}=0.1802$ to $1.0264, \mathrm{p}<0.01$ ) of plant leaf extract (fig. 5).

Pearson's bivariate correlation analysis showed significant, negative relationship between concentration of fluoride and activity of SOD in spermatozoa of test rats after $20(\mathrm{r}=-0.607, \mathrm{p}<0.01$, fig. $6 \mathrm{~A})$ and $40 \mathrm{~d}$ $(\mathrm{r}=-0.898, \mathrm{p}<0.0001$, fig. 6B) of fluoride intoxication.
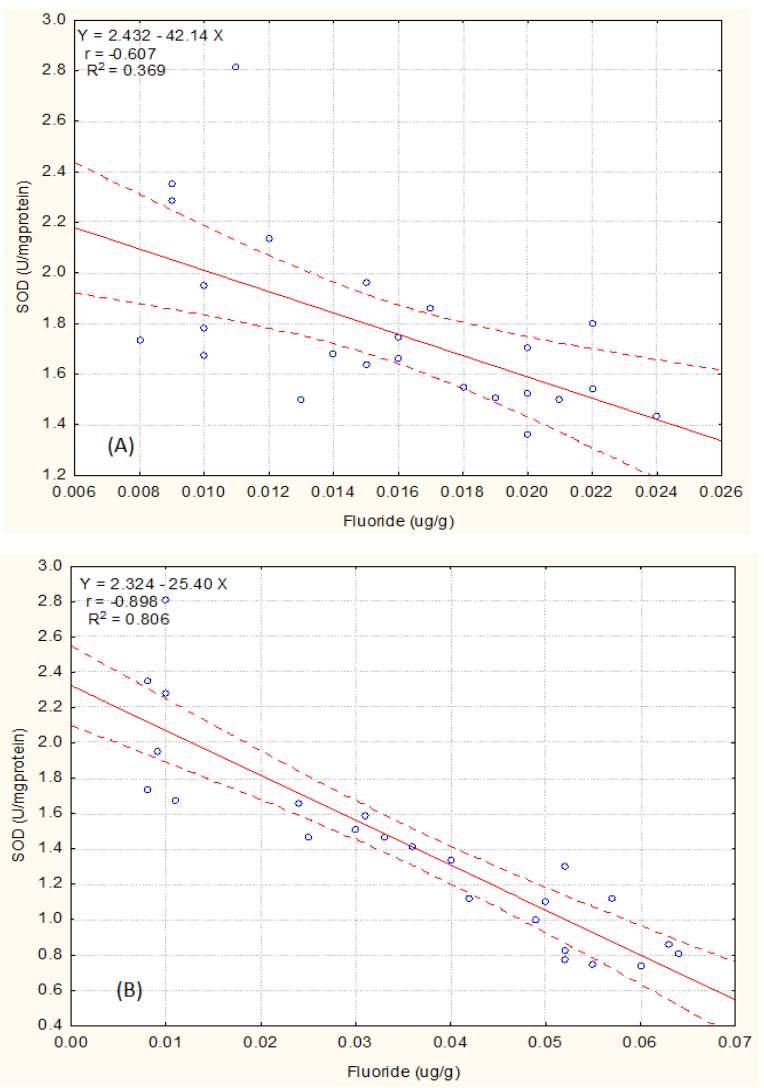

Fig. 6: Correlation and linear regression between fluoride level and activity of SOD in spermatozoa after (A) 20 and (B) $40 \mathrm{~d}$ of fluoride intoxication

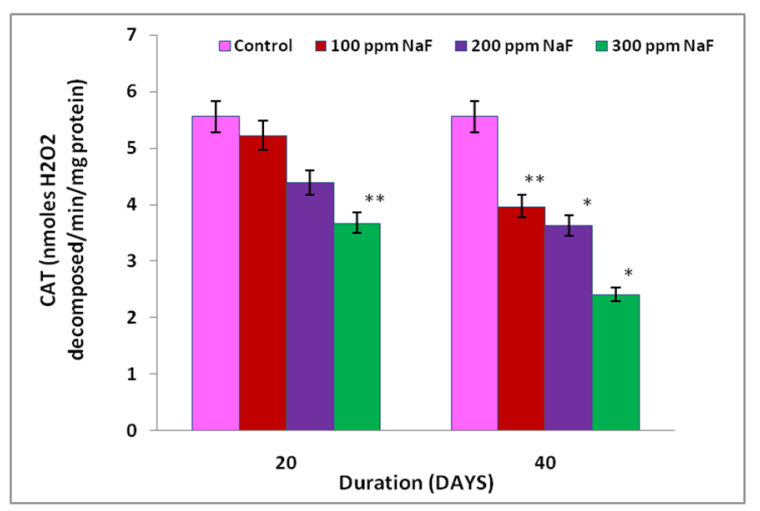

Fig. 7: Activity of CAT in control and NaF treated rats, values are expressed as mean \pm SD. ${ }^{*} p<0.0001$ and ${ }^{* *}$ p $<0.01$ and $\mathrm{NaF}$ treated groups compared with control

\section{Catalase (CAT) activity}

There was a significant decrease in the activity of CAT in spermatozoa of test rat after $20(\mathrm{~F}=5.942, \mathrm{p}<0.01)$ and $40 \mathrm{~d}$ $(\mathrm{F}=22.068, \mathrm{p}<0.0001)$ of fluoride treatment. 
Bonferroni multiple comparison tests after ANOVA showed that there was significant $(\mathrm{p}<0.05)$ decrease in the activity of CAT between and within groups treated with fluoride for $20(95 \% \mathrm{CI}=$ 0.1070 to 2.9853$)$ and $40 \mathrm{~d}(95 \% \mathrm{Cl}=0.4112$ to 2.3597 ; fig. 7$)$.

Dunnetts $\mathrm{t}$ ( 2 sided) multiple comparison tests revealed that activity of CAT in spermatozoa was significantly $(\mathrm{p}<0.05)$ increased in all rats post-treated with $500 \mathrm{mg} / \mathrm{kg}$ bw/day $(95 \% \mathrm{CI}=0.3446$ to 4.1137) of plant leaf extract (fig. 8).

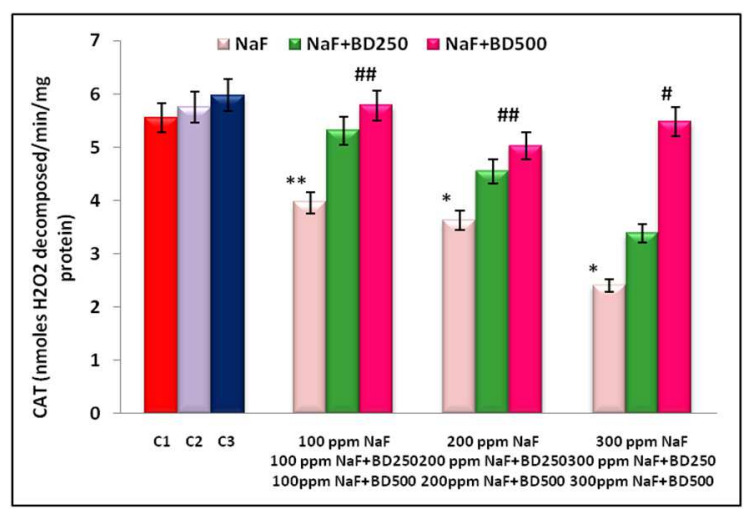

Fig. 8: Activity of CAT in spermatozoa of control (C1), positive control ( $\mathrm{C} 2$ and $\mathrm{C} 3$ ), $\mathrm{NaF}$ treated and the combination of $\mathrm{NaF}$ and leaf extract treated group. Values are represented as mean $\pm S D,{ }^{*} p<0.0001$ and ${ }^{* *} p<0.01$ compared with control (C1).

${ }^{\#} \mathbf{p}<0.001$ and ${ }^{\# \#} \mathbf{p}<0.05$ compared to respective NaF treated group

Pearson's bivariate correlation analysis indicated significant, negative relationship between concentration of fluoride and CAT activity after 20 ( $\mathrm{r}=-0.604, \mathrm{p}<0.01$, fig. 9A) and $40 \mathrm{~d}(\mathrm{r}=-0.819$, $\mathrm{p}<0.0001$, fig. 9B) of fluoride treatment.

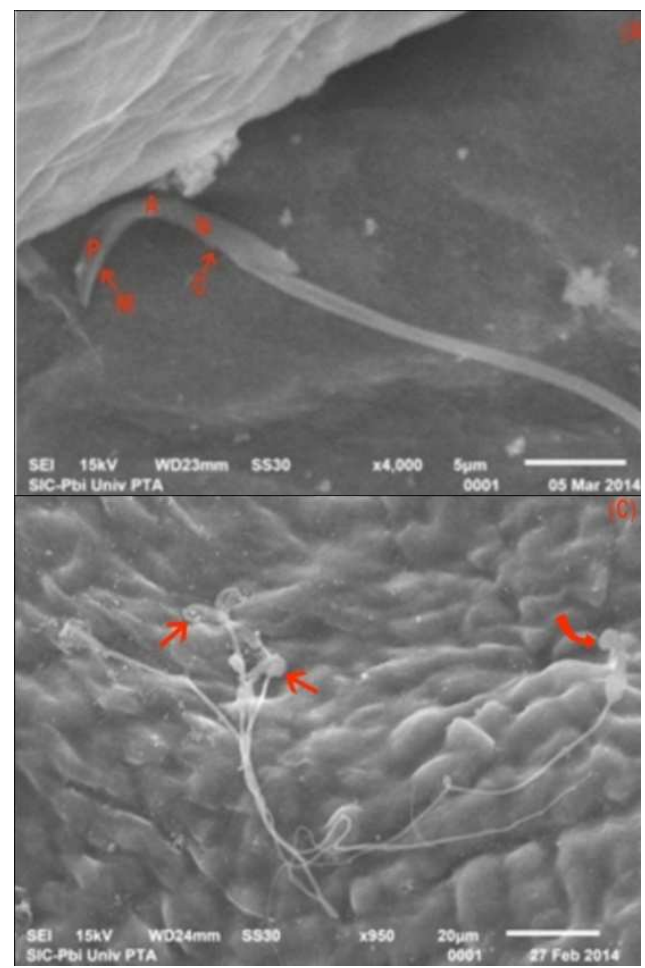

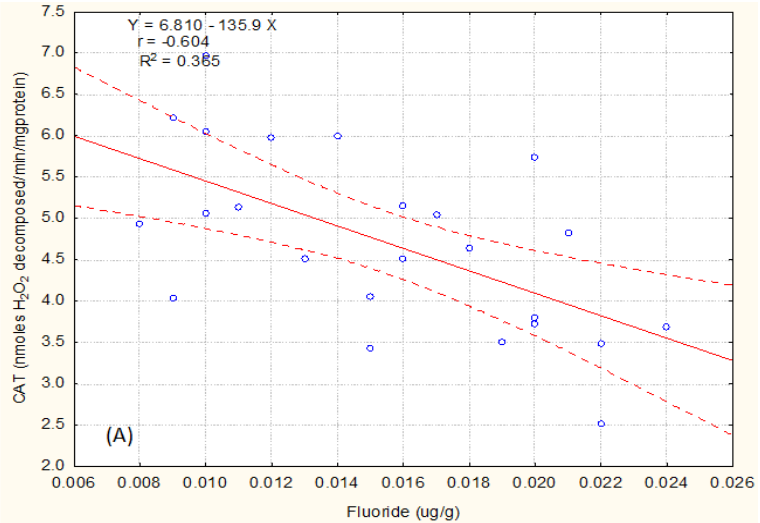

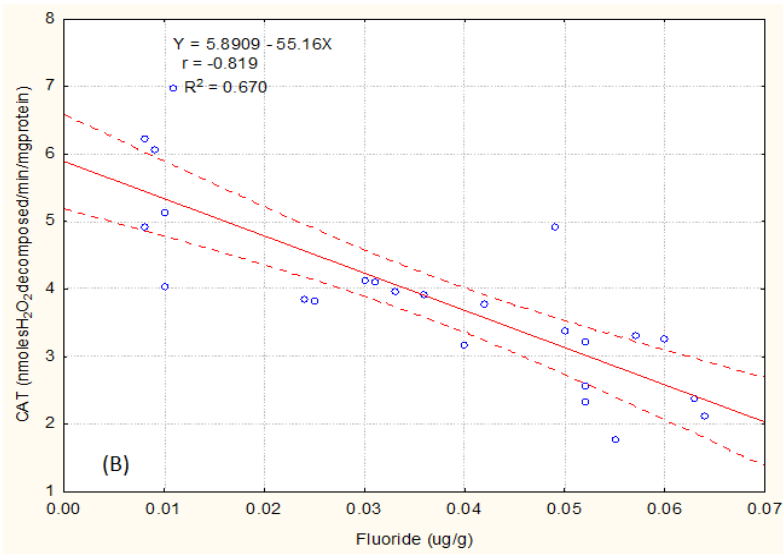

Fig. 9: Correlation and linear regression between level of fluoride and CAT activity in spermatozoa after (A) 20 and (B) 40 d of fluoride intoxication

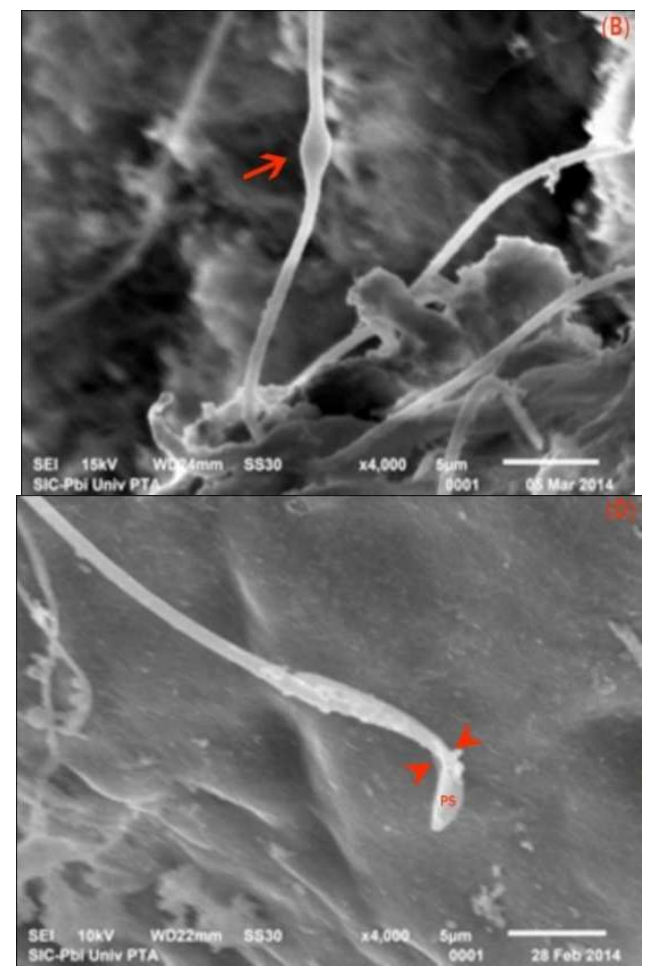

Fig. 10: Scanning electron micrographs of cauda epididymal spermatozoa of (A) Control and NaF treated rats (B, C and D), A. Spermatozoa of control rats exhibiting normal parts of acrosome (A); postnuclear cap(C); plasma membrane (M); nucleus (N); Perforatium (P) and tail region

(T). B. Balloon-like cytoplamic droplet in the mid portion of the tail region (arrow), C. Spermatozoa with hookless (curved arrow) and amorphous head (arrow), D. The perforation swells (PS) and the middle region of the sperm head is constricted dorsoventrally (arrow) 


\section{Sperm morphology}

SEM observations of cauda epididymal sperms of control rats were normal without any defects (fig. 10A). In control rat spermatozoa perforatorium and acrosome were covered with the plasma membrane. Whereas in fluoride-treated groups many morphologically-altered sperms were observed. In 200 and 300 ppm NaF group the shape and size of the sperm head was also changed considerably. There was an acute dorsoventral constriction in the mid-head region of most sperms. The perfortorium was bulged. Most of the spermatozoa showed splitting of the tail and distinct visibility of balloon-like cytoplasmic droplets in the mid-region of the tail (fig. 10B-D).

Various anomalies were observed in the sperms of rats exposed to fluoride. Maximum anomalies (336.11\%) were observed in the group treated with the highest dose of $\mathrm{NaF}$.

In control rat spermatozoa with hooked head and straight tail were found (fig. 11). Whereas, in $100 \mathrm{ppm} \mathrm{NaF}$ treated group tail abnormalities like coiled/folded and hairpin looped (fig. 12) and bent head, curved hook and bend neck were prevalent (fig. 13 a, fig. $14 \mathrm{a}$ and $\mathrm{c}$ ).

In rats treated with $200 \mathrm{ppm}$ spermatozoa with coiled/folded and constricted tail were common (fig. $15 \mathrm{~b}$ and d, fig. $16 \mathrm{a}, \mathrm{b}$ and c). The head abnormalities found were classified as amorphous, bent head and hookless head (fig. 13 b, fig. 14 b).
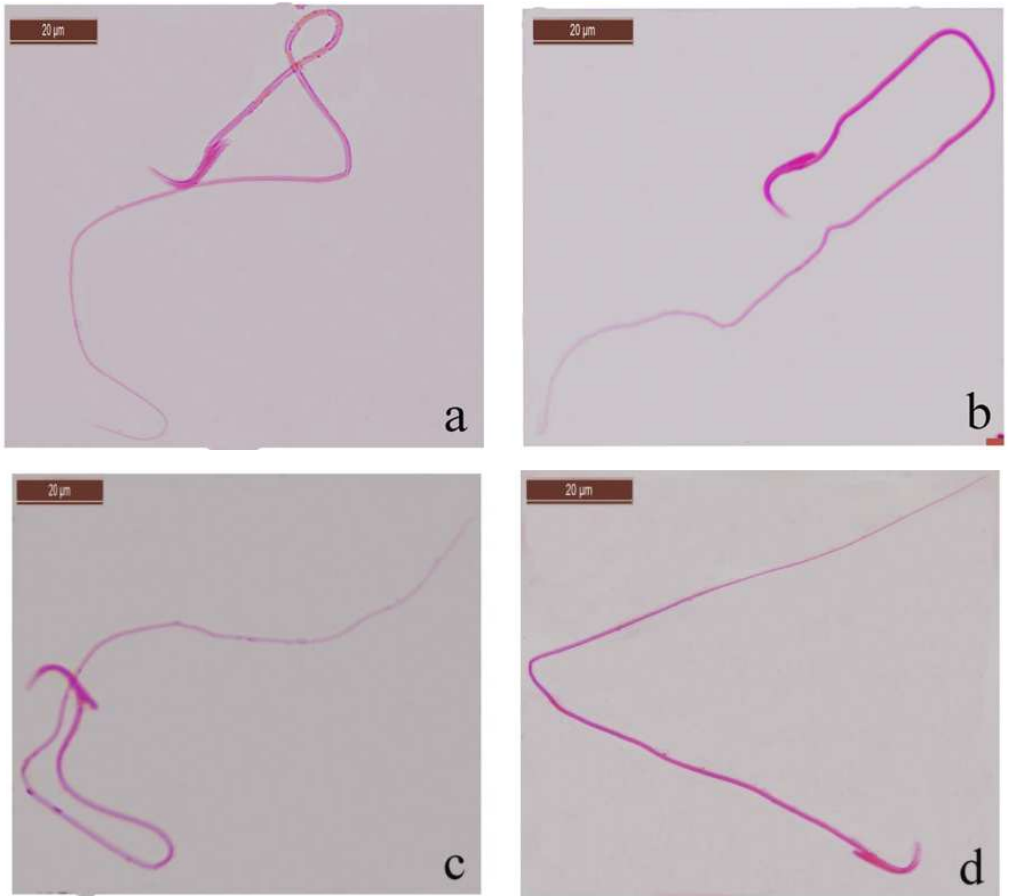

Fig. 12: Photomicrographs of cauda epididymal spermatozoa with coiled tail (a and c) and with hairpin loop (band d) in $100 \mathrm{ppm} N a F$ treated group (Eosin X1000)
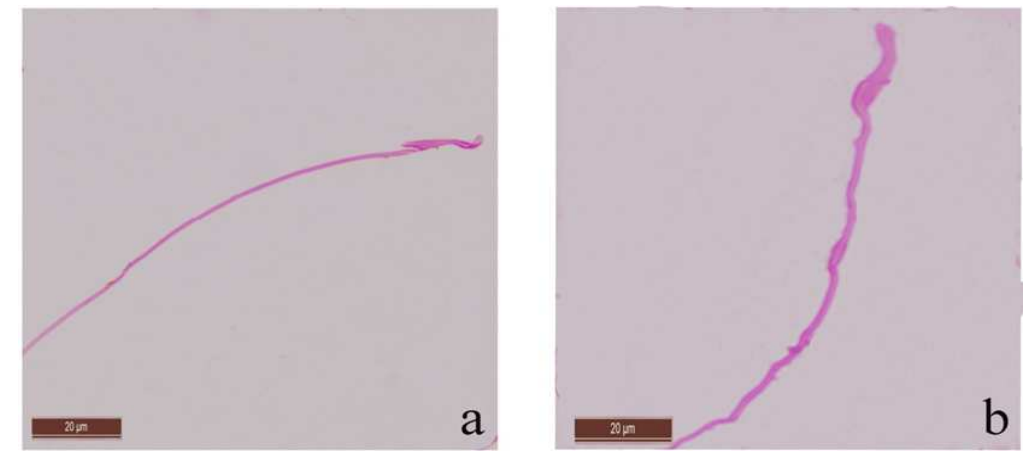

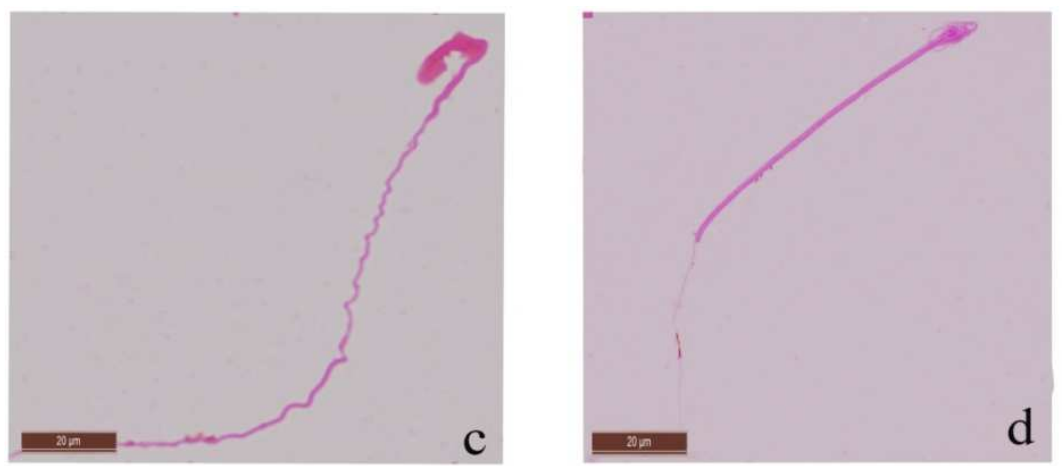

Fig. 13: Photomicrographs of cauda epididymal spermatozoa of rats with curved hook (a) in 100 ppm NaF group, without hook (b) in 200 ppm NaF group, head bent and constricted tail (c) in 300 ppm NaF group and with amorphous head and short tail (d) in 300 ppm NaF group (Eosin X1000)
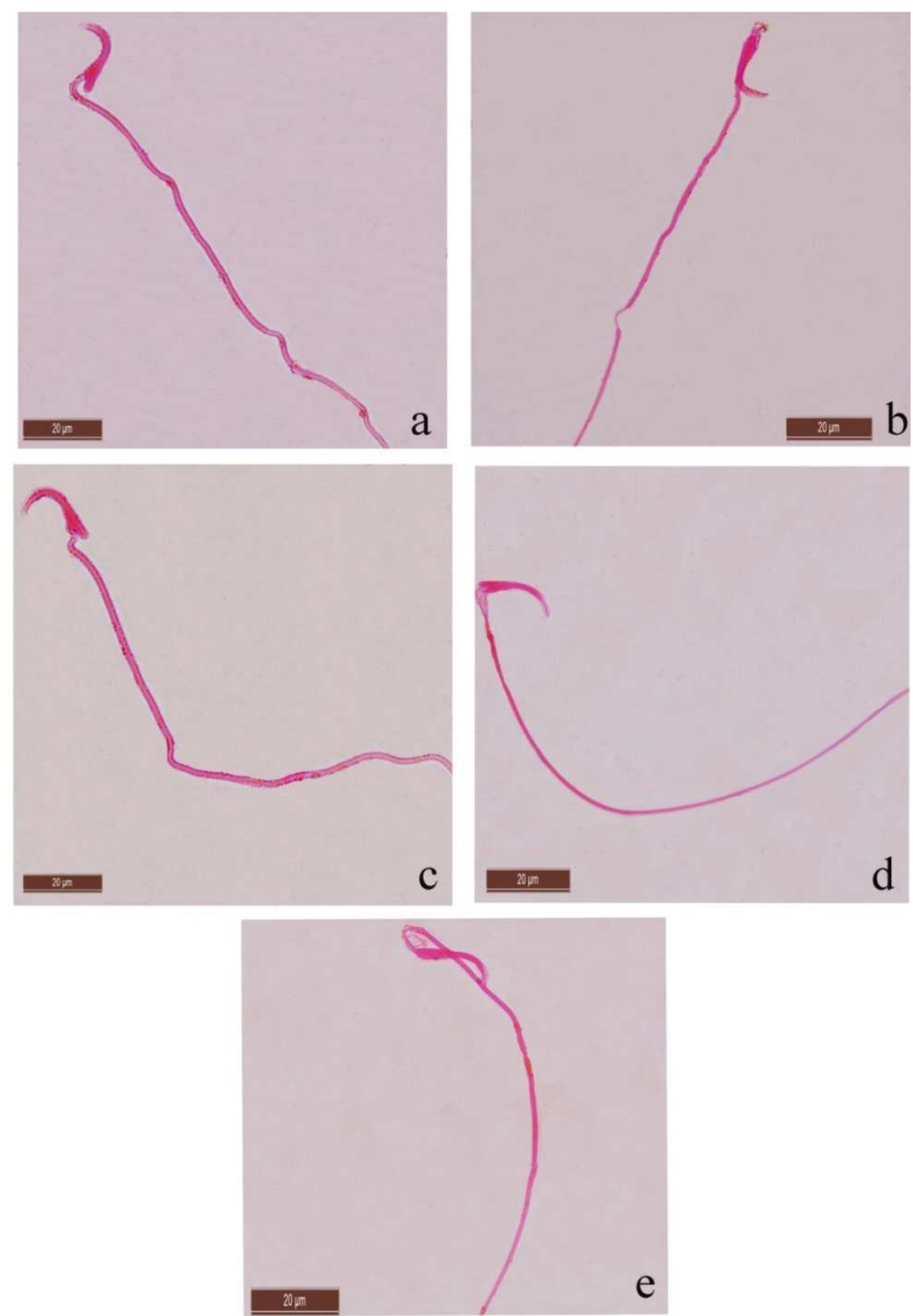

Fig. 14: Photomicrographs of cauda epididymal spermatozoa of rats with bent neck (a and c) in $100 \mathrm{ppm}$ NaF group, bent head (b) in 200 ppm NaF group, and with distorted neck ( $d$ and e) in 300 ppm NaF treated group (Eosin X1000) 

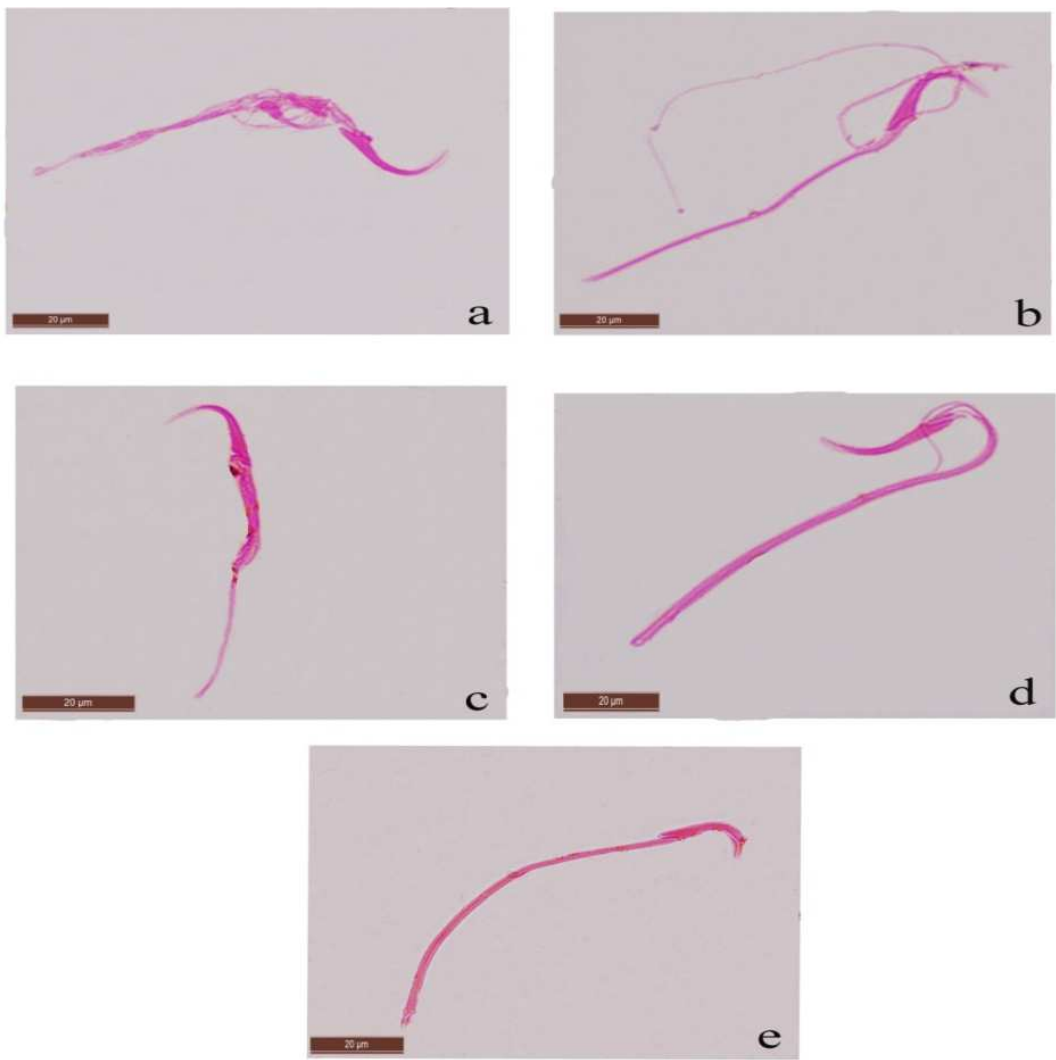

Fig. 15: Photomicrographs of cauda epididymal spermatozoa with deformed tail region (a, b, c, d and e) in 200 and 300 ppm NaF treated group (Eosin X1000)
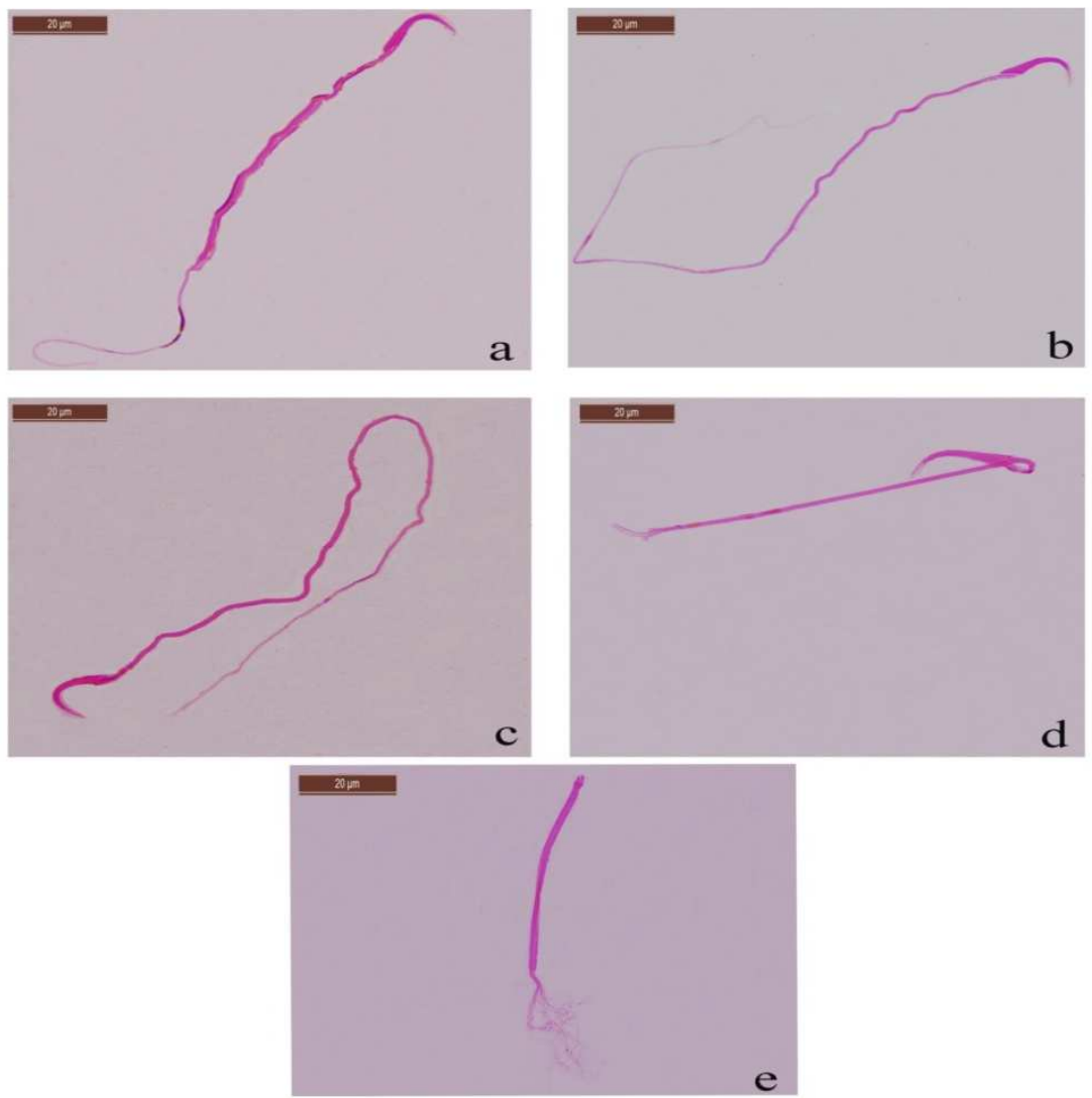

Fig. 16: Photomicrographs of cauda epididymal spermatozoa with deformed tail region (a, b, c and d) in 200 and 300 ppm NaF group and with multiple tail (e) in 300 ppm NaF group (Eosin X1000) 

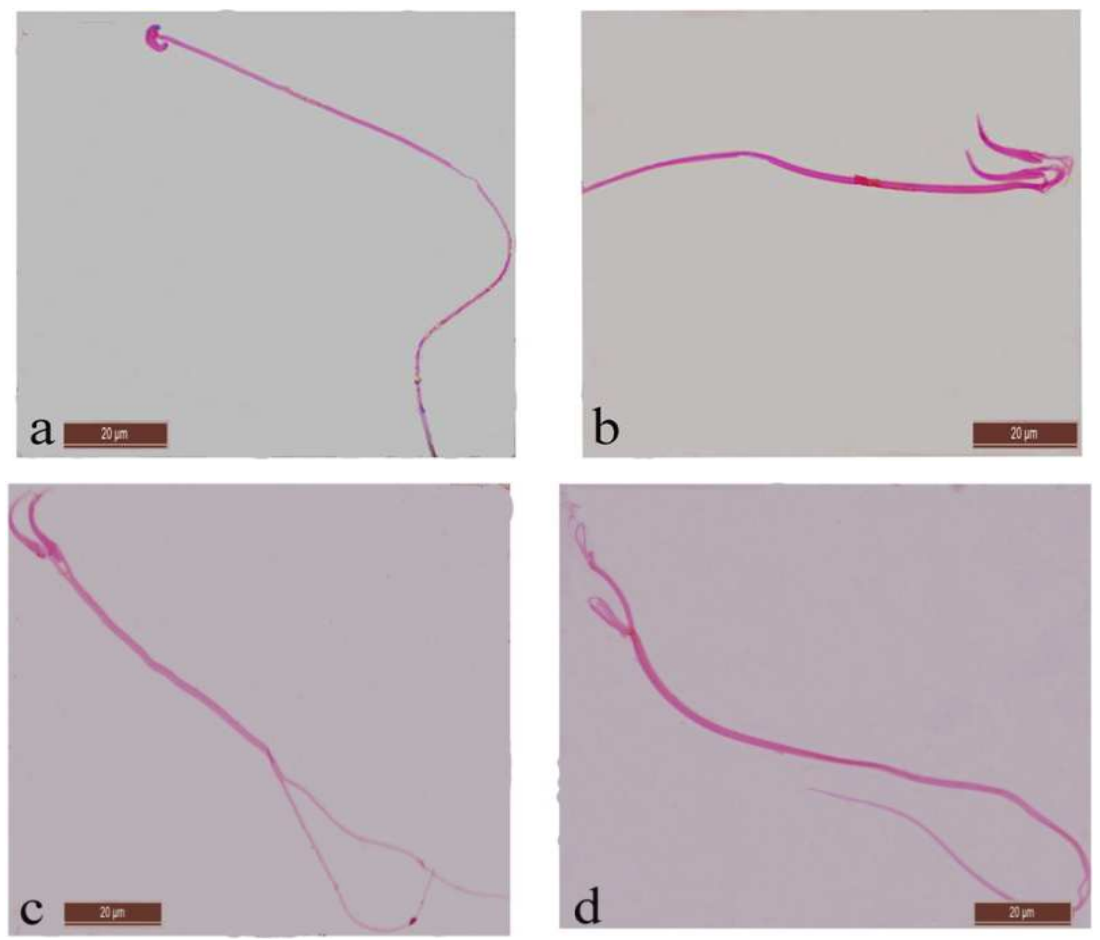

Fig. 17: Photomicrographs of cauda epididymal spermatozoa of rats with small head (a), with double head (b), with double head and double tail (c) and with amorphous double head (d) (Eosin X1000) in 300 ppm NaF treated groups

The abnormality in spermatozoa was significantly $(\mathrm{p}<0.0001)$ increased after $20(\mathrm{~F}=92.439)$ and $40 \mathrm{~d}(\mathrm{~F}=315.706)$ of fluoride treatment.

Bonferroni multiple comparison tests after ANOVA showed a significant increase in the sperm abnormality ( $\mathrm{p}<0.01,95 \% \mathrm{CI}=-14.4814$ to-5.3519) for 20 and $40 \mathrm{~d}(\mathrm{p}<0.0001,95 \% \mathrm{CI}=-22.8395$ to-14.3272) as compared to control as well as among fluoride-treated groups (fig. 18).

Dunnetts $\mathrm{t}$ ( 2 sided) multiple comparison tests revealed that sperm abnormality was significantly $(\mathrm{p}<0.0001)$ decreased in rats post-treated with 250 (95\% CI=-15.5221 to-8.5350) and $500 \mathrm{mg} / \mathrm{kgbw} /$ day $(95 \%$ $\mathrm{CI}=-22.1887$ to-28.2017) of leaf extract of $B$. diffusa (fig. 19).

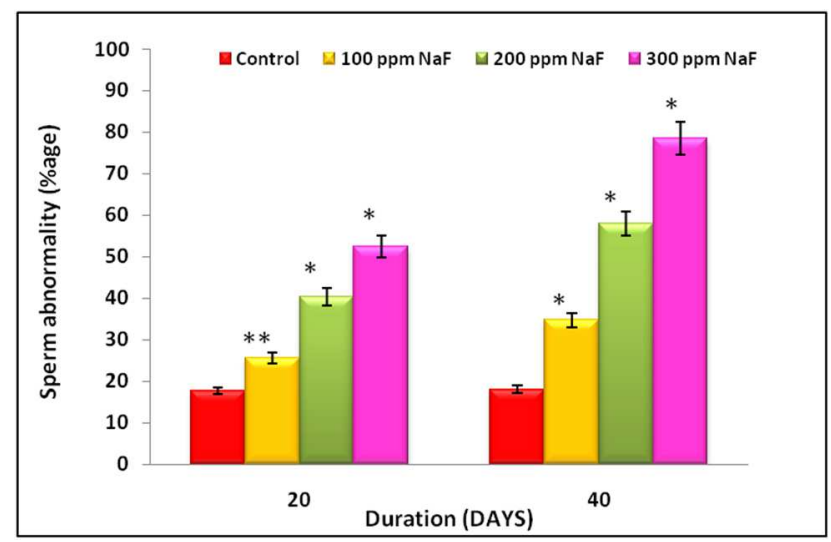

Fig. 18: Percentage of sperm abnormality in control and NaF treated rats. Values are expressed as mean \pm SD. ${ }^{*} \mathbf{p}<0.0001$ and ${ }^{* *} \mathbf{p}<0.05 \mathrm{NaF}$ treated groups compared with control

Pearson's bivariate correlation and simple linear regression analysis indicated significant $(\mathrm{p}<0.0001)$ positive relationship between the level of fluoride and sperm abnormality of test rats after $20(\mathrm{r}=-0.889$, fig. $20 \mathrm{~A})$ and $40 \mathrm{~d}(\mathrm{r}=-0.938$, fig. 20B) of fluoride treatment.

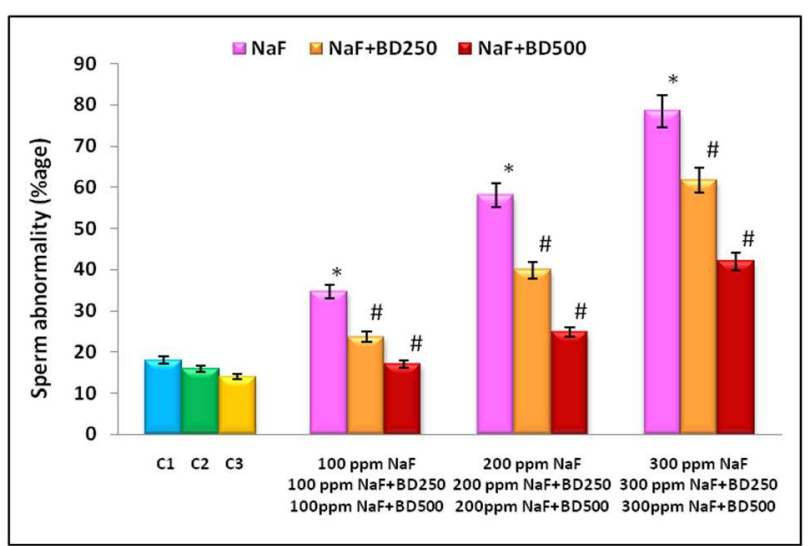

Fig. 19: Percentage sperm abnormality in control (C1), positive control (C2 and C3), NaF treated and the combination of NaF and leaf extract treated group. Values are represented as mean $\pm S D,{ }^{*} p<0.0001$ compared with control (C1). ${ }^{\#} p<0.0001$ compared to respective $\mathrm{NaF}$ treated group

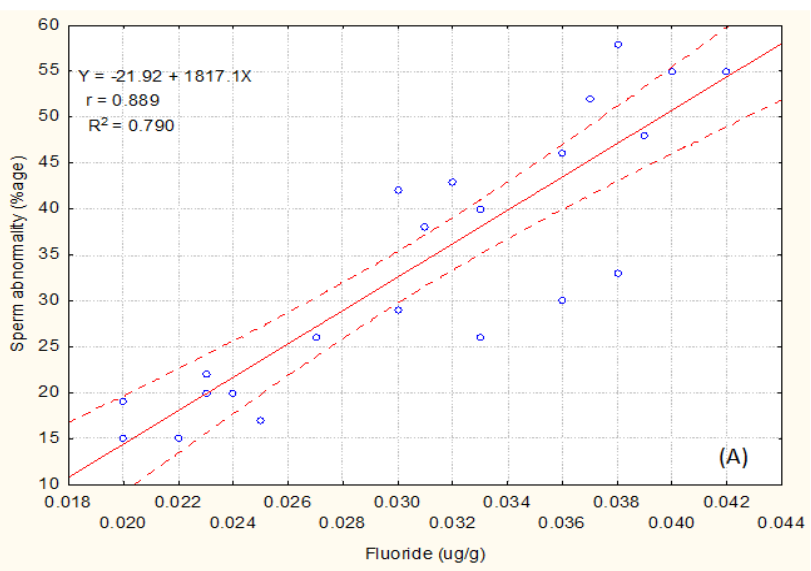




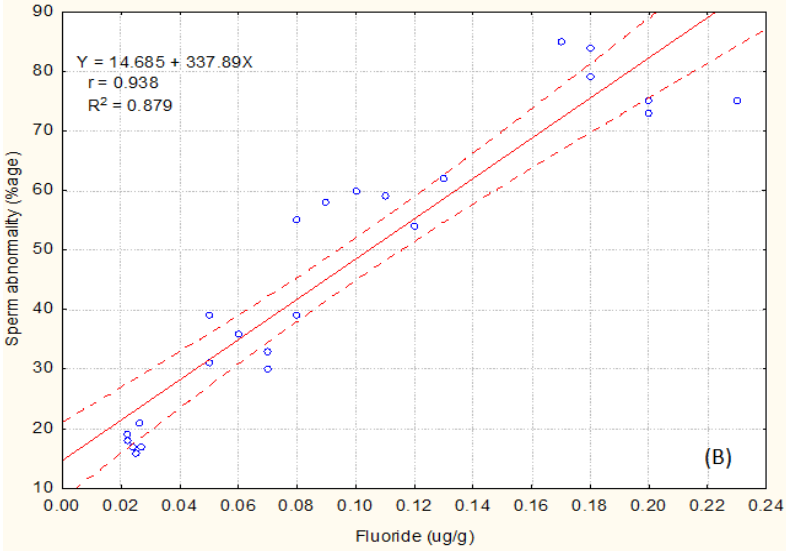

Fig. 20: Correlation and linear regression between level of fluoride in spermatozoa and percentage sperm abnormality after (A) 20 and (B) $40 \mathrm{~d}$ of fluoride intoxication

\section{Sperm count, motility and viability}

After $20 \mathrm{~d}$ of fluoride administration, there was significant $(\mathrm{p}<0.0001)$ decreased in sperm count $(\mathrm{F}=414.511)$, motility $(\mathrm{F}=420.388)$ and viability $(\mathrm{F}=32.966)$.

Bonferroni multiple comparison test after ANOVA disclosed a significant $(\mathrm{p}<0.0001)$ decrease in the sperm count $(95 \% \mathrm{CI}=3.8170$ to 3.6247 , fig. 21$)$, motility ( $95 \% \mathrm{CI}=9.8090$ to 14.4873 , fig. 22$)$ and viability $(95 \% \mathrm{CI}=5.9000$ to 38.6000 , fig. 23 ) as compared to control as well as among fluoride-treated groups after $20 \mathrm{~d}$ of fluoride treatment.

After $40 \mathrm{~d}$ of fluoride administration, there was significant $(\mathrm{p}<0.0001)$ decreased in sperm count $(\mathrm{F}=564.450)$, motility $(\mathrm{F}=790.056)$ and viability $(\mathrm{F}=93.535)$.

Bonferroni multiple comparison test after ANOVA unclosed a significant $(\mathrm{p}<0.0001)$ decrease in the sperm count $(95 \% \mathrm{CI}=6.9935$ to 3.8565 , fig. 21$)$, motility $(95 \% \mathrm{CI}=28.4974$ to 11.8213 , fig. 22$)$ and viability $(95 \% \mathrm{CI}=21.6595$ to 24.8405 , fig. 23$)$ as compared to control as well as among fluoride-treated groups after treatment with fluoride for $40 \mathrm{~d}$.

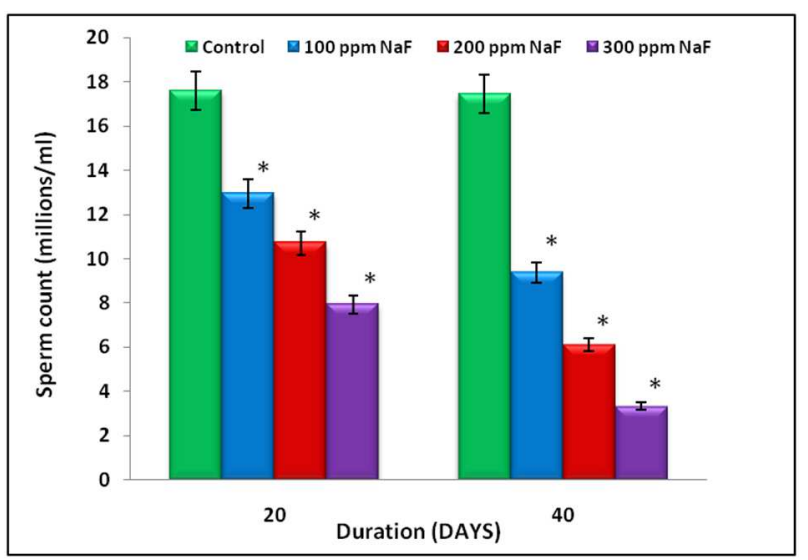

Fig. 21: Sperm count in control and $\mathrm{NaF}$ treated rats, values are expressed as mean $\pm S D$. ${ }^{*} p<0.0001 \mathrm{NaF}$ treated groups compared with control

Dunnetts $\mathrm{t}$ ( 2 sided) multiple comparison test revealed there was significant $(\mathrm{p}<0.0001)$ increase in sperm count $(95 \% \mathrm{CI}=4.4801$ to 5.9338, fig. 24), motility ( $95 \% \mathrm{CI}=19.6623$ to 23.3790 , fig. 25$)$ and viability $(95 \% \mathrm{CI}=8.3735$ to 33.7495 , fig. 26$)$ in rats treated with $250 \mathrm{mg} / \mathrm{kgbw} /$ day plant leaf extract.

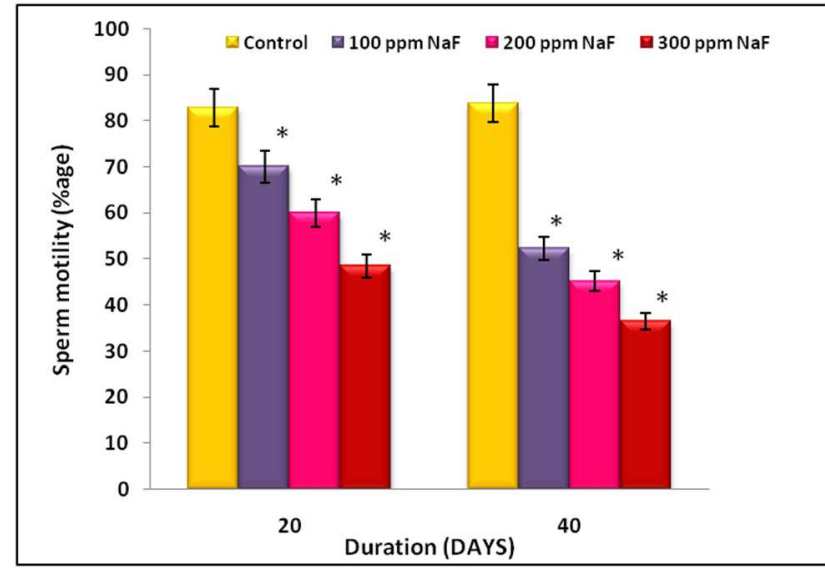

Fig. 22: Percentage of sperm motility in control and NaF treated rats, Values are expressed as mean \pm SD. ${ }^{*} p<0.0001 \mathrm{NaF}$ treated groups compared with control

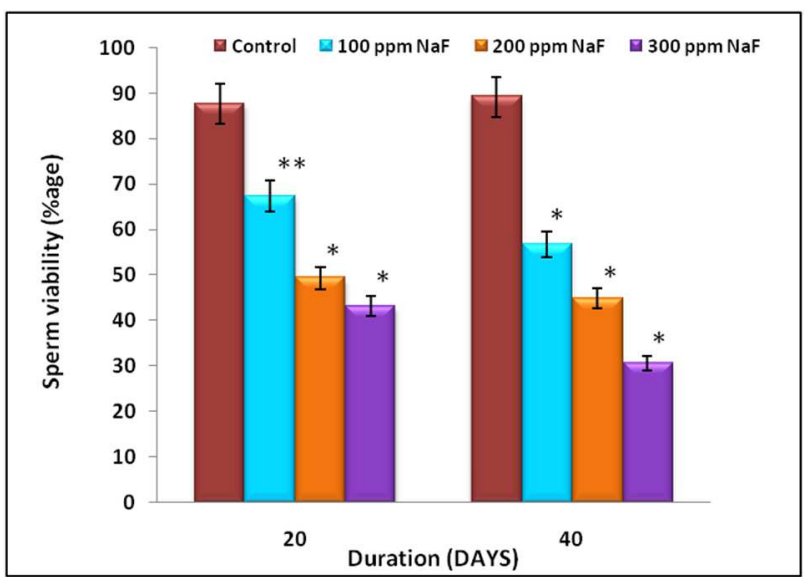

Fig. 23: Percentage of sperm viability in control and NaF treated rats, Values are expressed as mean \pm SD. ${ }^{*} \mathbf{p}<0.0001$ and ${ }^{* *}$ p $<0.01$ $\mathrm{NaF}$ treated groups compared with control

Further, Dunnetts $\mathrm{t}$ ( 2 sided) multiple comparison test after administration of $500 \mathrm{mg} / \mathrm{kgbw} /$ day leaf extract showed significant $(\mathrm{p}<0.0001)$ increase in sperm count $(95 \% \mathrm{CI}=6.3301$ to 8.8255 , fig. $24)$, motility ( $95 \% \mathrm{CI}=25.6227$ to 36.0132 , fig. 25$)$ and $(95 \% \mathrm{CI}=$ 20.3735 to 46.2495 , fig. 26) in rats treated with of plant leaf extract.

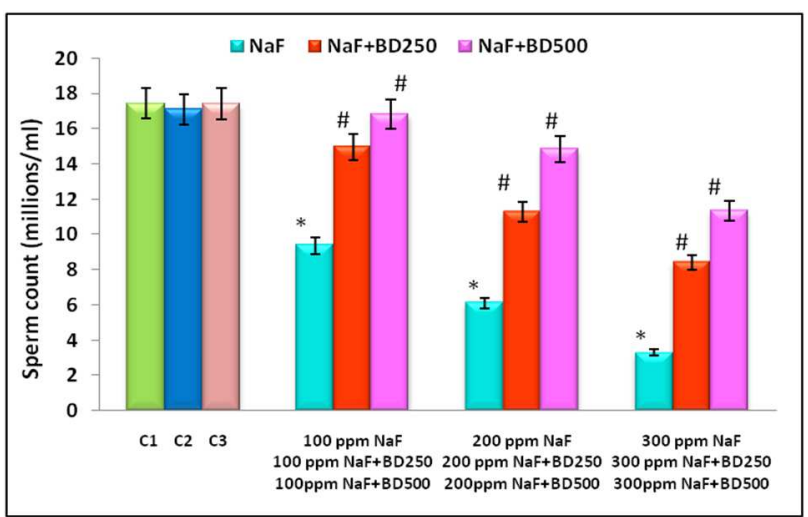

Fig. 24: Sperm count in control (C1), positive control (C2 and C3), NaF treated and the combination of $\mathrm{NaF}$ and leaf extract treated group, Values are represented as mean \pm SD. ${ }^{*} \mathbf{p}<0.0001$ compared with control (C1). ${ }^{*} \mathbf{p}<\mathbf{0 . 0 0 0 1}$ compared to respective NaF treated group 


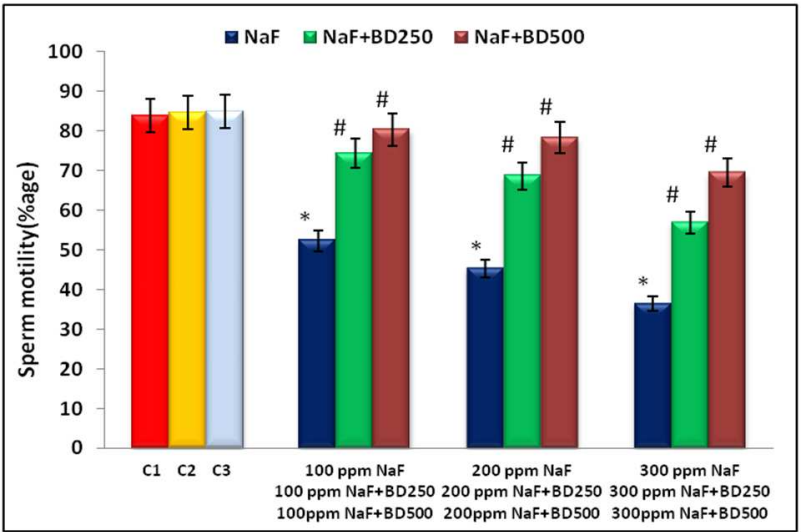

Fig. 25: Percentage sperm motility in control (C1), positive control (C2 and C3), NaF treated and the combination of $\mathrm{NaF}$ and leaf extract treated group. Values are represented as mean $\pm S D .{ }^{*} p<0.0001$ compared with control (C1). ${ }^{\#} p<0.0001$ compared to respective $\mathrm{NaF}$ treated group

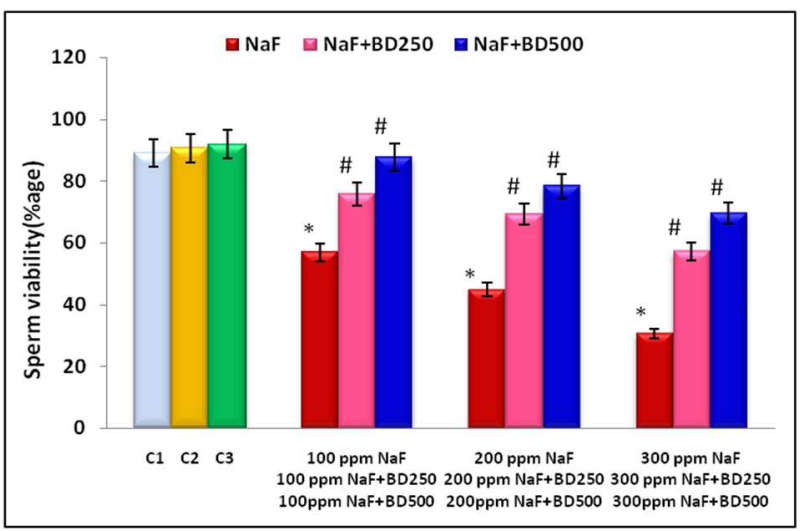

Fig. 26: Percentage sperm viability in control (C1), positive control (C2 and C3), NaF treated and the combination of NaF and leaf extract treated group, values are represented as mean $\pm S D .{ }^{*} p<0.0001$ compared with control (C1). ${ }^{\#} \mathbf{p}<0.0001$ compared to respective $\mathrm{NaF}$ treated group

Pearson's bivariate correlation analysis showed significant $(\mathrm{p}<0.0001)$ negative relationship between level of fluoride and sperm count $(\mathrm{r}=-0.895$, fig. $27 \mathrm{~A} ; \mathrm{r}=-0.946$, fig. $28 \mathrm{~A})$, motility $(\mathrm{r}=-$ 0.899 , fig. 27B; $r=-0.934$, fig. 28B) and viability ( $r=-0.742$, fig. $27 \mathrm{C} ; \mathrm{r}$ $=-0.926$, fig. $28 \mathrm{C}$ ) of experimental rats after 20 and $40 \mathrm{~d}$ of fluoride treatment respectively.

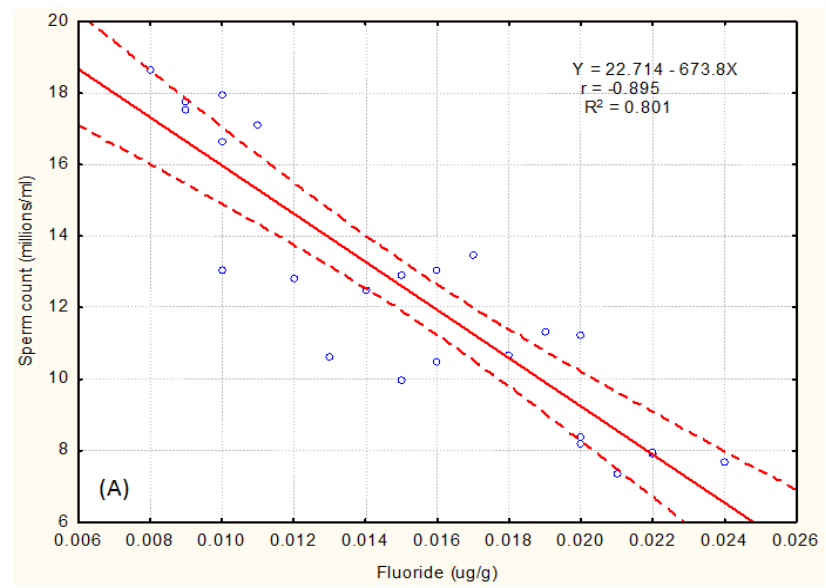

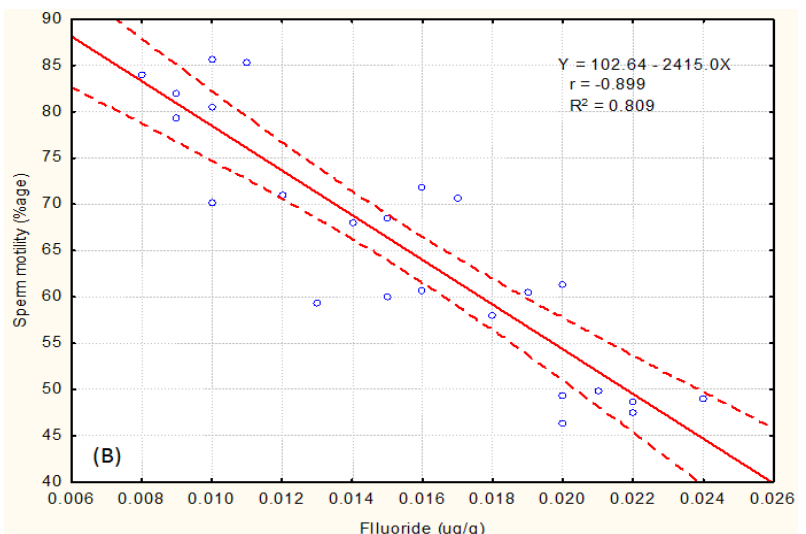

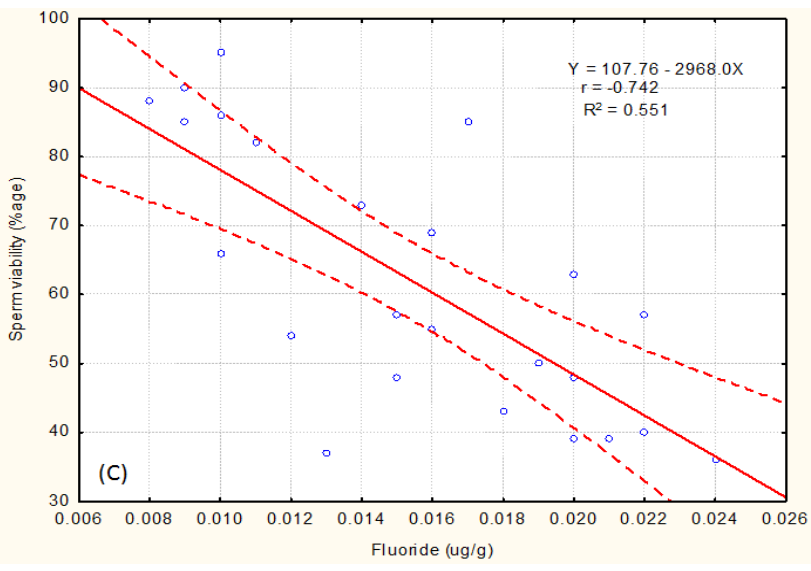

Fig. 27: Correlation and linear regression between level of fluoride and (A) sperm count, (B) sperm motility and (C) sperm viability after $20 \mathrm{~d}$ of fluoride intoxication
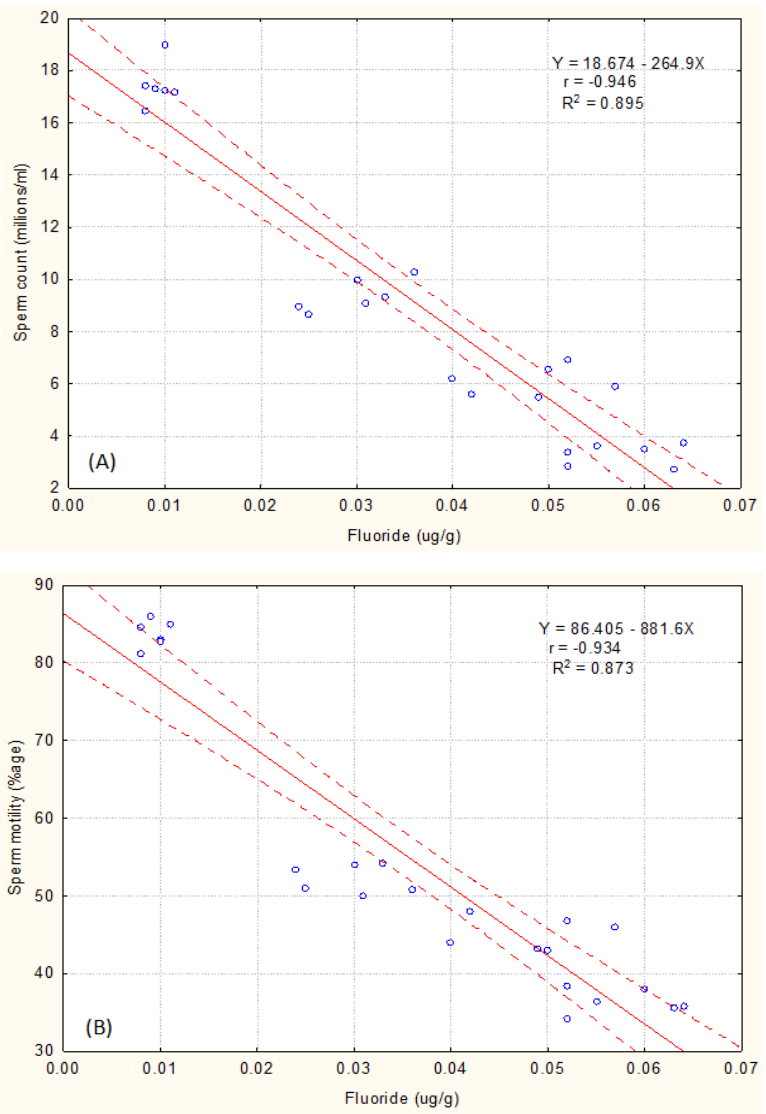


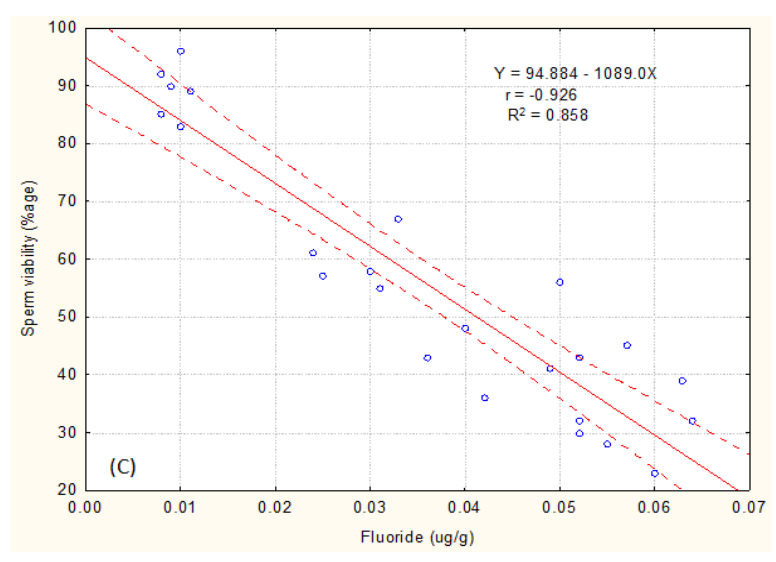

Fig. 28: Correlation and linear regression between level of fluoride and (A) sperm count, (B) sperm motility and (C) sperm viability after $40 \mathrm{~d}$ of fluoride intoxication

\section{DISCUSSION}

The present investigation was carried out to explore the effects of fluoride and the possible alleviation by $B$. diffusa leaf extract on antioxidant status and sperm quality of rat. Reproductive anomalies due to the toxic exposure in males are one of the fastest growing areas of concern in toxicology. Fluoride ion is able to exert powerful effects on various enzymes that affect the status of oxidant/antioxidant systems in the living organism. It is reported that fluoride exposure leads to oxidative stress as indicated by an increased level of lipid peroxide products in the testis, epididymis and epididymal sperm with respect to control [17-18].

As evident in our study, we observed significant $(p<0.0001)$ elevation as compared to control in the level of MDA in rats treated with fluoride alone. On the other hand, the activities of both SOD and CAT declined significantly $(\mathrm{p}<0.01)$. While the administration of $B$. diffusa extract attenuates the oxidative damage caused by fluoride exposure as evident by significant $(\mathrm{p}<0.0001)$ decline in the level of MDA and significant $(p<0.01)$ elevation in the activity of both SOD and CAT.

Previous studies have demonstrated that fluoride increases lipid peroxidation through the generation of reactive oxygen species (ROS) [19]. Since sperm plasma membrane is composed of polyunsaturated fatty acids and they are highly susceptible to lipid peroxidation and protein oxidation [20]. Studies have also revealed that fluoride reduces the activities of SOD and CAT in testis and sperm, which protects sperm from oxidative attack and whose deficiency correlated with male infertility [21], and the alleviation of the fluoride toxicity by additional antioxidants has been confirmed $[18,22]$. Effect of fluoride on SOD activity in spermatozoa may be by acting as an inhibitor of Mn-SOD and $\mathrm{Cu} / \mathrm{Zn} \mathrm{SOD,} \mathrm{their} \mathrm{proposed}$ mechanism involves its binding to the divalent cofactors in active site on SOD. SOD inactivation would lead to increased levels of superoxide anion within the mitochondria which, could lead to oxidation of key mitochondrial proteins and ultimately mitochondrial dysfunction and cell death.

The changes in the indicated parameters suggest the activities of antioxidant enzymes to be insufficient in the compensation of free radicals generated at a high level upon the administration of fluoride at the indicated dose and for the indicated period. For, the increase in the MDA level also confirms this situation. The decrease in the activities of the enzymes can be explained either with their consumption and induction during the conversion of free radicals into less harmful or harmless metabolites or secondarily with the direct inhibitory or stimulatory effect of fluoride on enzyme activity. Amongst relevant studies that have been conducted in various animal species, fluoride has been reported to cause changes in oxidative stress markers in various biological materials [23-24].

The defective sperm with abnormalities in the head, midpiece, and tail have a highly reactive oxygen species (ROS) production $[21,25]$.
Fluoride has been determined to cause a significant increase in sperm abnormality [26], which provides a strong pathological basis for excessive ROS presence. ROS can directly attack polyunsaturated fatty acid on the sperm membrane, inducing lipid peroxidation, damaging the membrane integrity, destroying the structure of axoneme, and finally reducing sperm activity and fertility [27-28]. Sperm with any abnormal morphology could result in the low function, adversely impacting on the successful fertilization. There was significant $(\mathrm{p}<0.05)$ increase observed in the number of abnormal sperms at days 20 and 40, respectively. However, administration with $B$. diffusa resulted in a decline in the number of spermatozoa with abnormal morphology.

In the present study, the sperm count, motility and viability of fluoridated groups were reduced significantly $(\mathrm{p}<0.0001)$. However, values pertaining to the groups that received $B$. diffusa extract in association with fluoride displayed significant $(\mathrm{p}<0.001)$ increase and reached close to the control group. The results of our study are in consonance with previously conducted studies [29-31].

The mechanism by which fluoride affects sperm motility has not been clearly elucidated. However, it has been postulated that fluoride could act directly on the motile apparatus without affecting other metabolic systems. One mechanism could be a decline in the fructose level, which provides energy for motility, due to alteration in carbohydrates metabolism. Fluoride also binds with cofactors like $\mathrm{Mg}, \mathrm{Ca}, \mathrm{Zn}$ and Se and thus inhibits glycolysis, respiration and motility of sperms [32]. Another reason for decreased sperm motility could be decreased in the level of androgen carrier proteins involved in sperm motility [33].

\section{CONCLUSION}

In conclusion, the result of this study has shown that oxidative stress in spermatozoa is evident during fluoride toxicity. The experimental study indicates that the fluoride toxicity produces definite effects on spermatozoa which are evident from morphological abnormalities and alterations in sperm quality parameters. These morphological anomalies may be induced by the mechanism of oxidative stress and interference in antioxidant defence mechanism. Furthermore, our study also implies that the administration of $B$. diffusa leaf extract plays an essential role in inhibiting the male reproductive damage caused by fluorosis and $B$. diffusa might act as an antidote against fluoride induced male reproductive toxicity.

\section{ACKNOWLEDGEMENT}

The financial assistance in the form of Innovation in science pursuit for an inspired research grant by Department of Science and Technology, Govt. of India is gratefully acknowledged.

\section{CONTRIBUTION OF AUTHORS}

Both the authors had contributed equally to the research work

\section{CONFLICT OF INTERESTS}

The authors declare that they have no conflicts of interests.

\section{REFERENCES}

1. Toft G, Rignell-Hydbom A, Tyrkiel E, Shvets M, Giwercman A, Lindh $\mathrm{CH}$, et al. Semen quality and exposure to persistent organochlorine pollutants. Epidemiol 2006;17:450-8.

2. Hansen C, Luben TJ, Sacks JD, Olshan A, Jeffay S, Strader L, et al. The effect of ambient air pollution on sperm quality. Environ Health Perspect 2010;118:203-9.

3. Xu R, Shang W, Liu J, Duan L, Ba Y, Zhang H, et al. Influence of fluorine on the expression of the androgen-binding protein and inhibin B mRNA in rat testis sertoli cells. Weisheng Yanjiu 2010;39:615-7.

4. Dvoraokovao-Hortovao K, Sandera M, Jursovao M, Vasinovao J, Peknicovao J. The influence of fluorides on mouse sperm capacitation. Anim Reprod Sci 2008;108:157-70.

5. Sun Z, Niu R, Su K, Wang B, Wang J, Zhang J, et al. Effects of sodium fluoride on hyperactivation and $\mathrm{Ca} 2+$ signaling pathway in sperm from mice: an in vivo study. Arch Toxicol 2010;84:353-61. 
6. Shrader Frechette K. EPA's 2006 human-subjects rule for pesticide experiments. Account Res 2007;14:211-54.

7. Gaitonde BB, Kulkarni HJ, Nabar SD. Diuretic activity of punarnava (Boerhaavia diffusa). Bulletins of the Haffkine Institute (Bombay, India); 1974.

8. Mudgal V. Studies on medicinal properties of Convolvulus pluricaulis and Boerhaavia diffusa. Planta Med 1975;28:62-8.

9. Premkumar P, Priya J, Suriyavathana M. Evaluation of antioxidant potential of andrographis echioides and Boerhaavia diffusa. Int J Curr Res 2010;3:59-62.

10. Narendhirakannan RT, Subramanian S, Kandaswamy M. Biochemical evaluation of antidiabetogenic properties of some commonly used Indian plants on streptozotocin-induced diabetes in experimental rats. Clin Exp Pharmacol Physiol 2006;33:1150-7.

11. Ohkawa H, Ohishi N, Yagi K. Assay for lipid peroxides in animal tissues by thiobarbituric acid reaction. Anal Biochem 1979;95:351-8.

12. Das K, Samanta L, Chainy GBN. A modified spectrophotometric assay for superoxide dismutase using nitrite formation by superoxide radicals. Indian J Biochem Biophysics 2000;37:201-4.

13. Aebi HE. Catalase in methods of enzymatic analysis. Bergmeyr HU. ed. Verlag chemie Weinhei 1983;3:273-86.

14. Bairy L, Paul V, Rao Y. Reproductive toxicity of sodium valproate in male rats. Indian J Pharmacol 2010;42:90-4

15. Flegler SL, Heckman JW, Klomparens KL. Scanning and transmission electron microscopy. WH Freeman and Company, New York; 1993.

16. Eliasson R. Supravital staining of human spermatozoa. Fertil Steril 1977;28:1257.

17. Susheela AK, Kumar A. Ultrastructural studies on the leydig cells of rabbits exposed to chronic fluoride toxicity. Environ Sci 1997;5:79-94.

18. Ghosh D, Das SS, Maiti R, Jana D, Das UB. Testicular toxicity in sodium fluoride treated rats: association with oxidative stress. Reprod Toxicol 2002;16:385-90.

19. Chauhan DS, Singh VP, Tripathi S, Tomar A, Tiwari M, Tomar S. Influence of fluoride exposure on hypothalamic pituitary gonadal axis hormones and semen quality. Asian J Biol Life Sci 2013;3:201-6.

20. Chauhan DS, Tomar A, Tiwari M, Singh VP, Tomar S, Tripathi S. Endogenous and exogenous antioxidants status in seminal plasma of skeletal fluorotic patients. Sch J Appl Med Sci 2013;1:152-7.

21. Agarwal A, Said TM. Oxidative stress, DNA damage and apoptosis in male infertility: a clinical approach. BJU Int 2005;95:503-7.
22. Wang JL, Zhang YM, Zhang HJ, Zhang K, Zhang ZW, Li J. Toxic effects of fluoride on reproductive ability in male rats: sperm motility, oxidative stress, cell cycle, and testicular apoptosis. Fluoride 2009;42:174-8.

23. Shivarajashankara YM, Shivashankara AR, Gopalakrishna Bhat $\mathrm{P}$, Hanumanth Rao S. Effects of fluoride intoxication on lipid peroxidation and antioxidant systems in rats. Fluoride 2001;34:108-13.

24. Mittal M, Flora SJ. Effects of individual and combined exposure to sodium arsenite and sodium fluoride on tissue oxidative stress, arsenic and fluoride levels in male mice. Chem Biol Interact 2006;162:128-39.

25. Aziz N, Saleh RA, Sharma RK, Lewis-Jones I, Esfandiari N, Thomas AJ, et al. Novel association between sperm reactive oxygen species production, sperm morphological defects, and the sperm deformity index. Fertil Steril 2004;81:349-54.

26. Chinoy NJ, Sharma A. Reversal of fluoride-induced alteration in cauda epididymal spermatozoa and fertility impairment in male mice. Environ Sci 2000; 7:29-38.

27. Saleh RA, Agarwal A. Oxidative stress and male infertility: from the research bench to clinical practice. J Androl 2002;23:737-52.

28. Kao SH, Chao HT, Chen HW, Hwang TI, Liao TL, Wei YH. Increase of oxidative stress in human sperm with lower motility. Fertil Steril 2008;89:1183-90.

29. Huang $\mathrm{C}$, Niu R, Wang J. Toxic effects of sodium fluoride on reproductive function in male mice. Fluoride 2007;40:162-8.

30. Wan SX, Zhang JH, Wang JD. Effects of high fluoride on sperm quality and testicular histology in male rats. Fluoride 2006;39:17-21.

31. Cui LX, Jiang CX, Wang XL, Chen XM. Experimental study on effect of fluoride on reproductive system of male rats. Chin J Endemiol 2003;22:195-7.

32. Huang C, Yang H, Niu R, Sun Z, Wang J. Effect of sodium fluoride on androgen receptor expression in male mice. Fluoride 2008;41:10-7.

33. Chinoy NJ, Shukla S, Walimbe AS, Bhattacharya S. Fluoride toxicity on rat testis and cauda epididymal tissue components and its reversal. Fluoride 1997;30:41-50.

\section{How to cite this article}

- Shashi A, Imtiaza Khan. Alleviation of fluoride-induced alterations in antioxidant status and fecundity of spermatozoa of rats by Boerhaavia diffusa L.. Int J Pharm Pharm Sci 2017;9(10):93-104. 